\title{
An Old Question Revisited: Current Understanding of Aging Theories
}

\author{
Tak Pan Wong ${ }^{* \dagger}$, Ph.D.
}

\begin{abstract}
Why we age" is no longer a solely philosophical question. In parallel with the rising awareness of the social ramifications of an aging population, basic research has expanded our understanding of the intricate nature of biological aging. The present paper aims at discussing our current understanding of the molecular and cellular alterations that accompany aging. To this end, the main theories on the mechanisms of aging, error theories and program theories, will be discussed. Special focus on neuronal aging is also presented to provide illustrative examples of these aging mechanisms.
\end{abstract}

\section{INTRODUCTION}

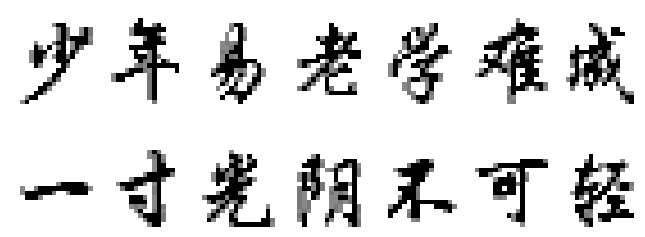

One rapidly becomes old, but learning is slow; therefore, never waste a moment.

While this ancient Chinese proverb describes the preciousness of every moment of our lifespan, it fits interestingly with the impact of aging on our society. The proportion of the aged population in the world is increasing rapidly. Taking Canada as an example, the population of over 65 is predicted to rise from the present 3.5 million to 7.7 million in the next 25 years (1). A similar trend can be found in the United States. The population of over 65- and over 85-years old is

\footnotetext{
* To whom correspondence should be addressed: Deptartment of Pharmacology and Therapeutics, McGill University, 3655 Promenade Sir William Osler, Montreal, QC, H3G 1Y6, Canada. E-mail: tpwong@pharma.mcgill.ca.

$\dagger$ Deptartment of Pharmacology and Therapeutics, McGill University.
}

expected to increase two and five fold respectively in the next 50 years (2). Indeed, thanks to the development of technology and medicine, our life expectancy has increased $50 \%$ in the last century (3). However, our understanding of the biological mechanisms underlying the aging process is progressing at a much slower pace. For instance, the prevalence of disabilities in the aging population has been decreasing only slowly in recent years (4). Indeed, health care spending for elders in the coming decades will become a substantial financial burden to our society (5).

This paper will explore general concepts of aging, including how we define aging and how aging occurs at the most basic molecular and cellular levels. As will become evident, both environmental and genetic factors interact through multiple different mechanisms to produce changes at the molecular and cellular levels that ultimately manifest themselves as changes that are more easily observed in tissues and organs, and in the organism as a whole. Identification of and response to these gross changes benefit from an understanding the underlying mechanisms that produced them. In the long term, a greater understanding of aging will provide solutions not only to reduce the burden caused by the aged population to the society but, more importantly, to extend the productive and healthy lifespan of the elderly in the future. 


\section{DEFINITIONS OF AGING}

Perhaps the association between aging and phenomena such as weakness, disease, and death is so strong that most definitions of aging have focused on the adverse characteristics in the last stage of life. Comfort in his book The Biology of Senescence has defined aging as:

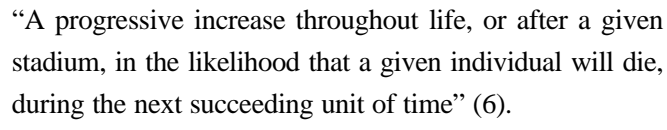

In Comfort's view, aging happens as a result of a progressive loss of physiological functions that culminates in death. Indeed, the progressiveness of the aging process has brought about the idea of "error accumulation' throughout the lifespan. For instance, Harman has defined aging as:

\footnotetext{
"The accumulation of changes responsible for the sequential alterations that accompany advancing age and the associated progressive increases in the chance of disease and death" (7).
}

Recent progress in aging research has led to frequent revisions of the definition of aging. For instance, Busse has divided the aging processes into primary and secondary aging (8). In his view, primary aging is intrinsic to the organism, and the detrimental factors are determined by inherent or hereditary influences. On the other hand, secondary aging is caused by deleterious or hostile factors in the environment. However, due to the complexity of the aging process, these descriptive definitions of aging are always far from satisfactory. Taking Busse's definition as an example, since both intrinsic and environmental factors have been shown to interact with each other during the development of various aging deficits, separating these factors into independent processes is not realistic.

While it is difficult to define aging, describing when aging begins is equally complicated. For example, even though the rat is the most commonly used mammalian model of aging, there are controversies in the definition of an aged rat. Some investigators consider any sexually mature rat to be old. Thus, 14-month-old rats have been regarded as aged rats (e.g. reference 9), whereas rats ranging from 24 to $30+$ month-old are used as reference for aged rats in other studies (e.g. references 10,11). One way to define the starting point of aging is to use survival curves (12). Survival curves are constructed by plotting the percentage survival against the age of individuals in a population. Rats can be considered as entering the aging stage when their survival percentage is lower than $50 \%$. For instance, based on survival curves of Sprague-Dawley (13), Wistar (14), Fischer (15), and Brown Norway rats (16), their $50 \%$ survival age ranged from 27 to 30 months.
While the focus here is admittedly biological, the social aspects of aging cannot be completely disregarded. For instance, in regards to what age would be considered 'old' for a person, the common answer would likely depend much more on social factors than on biological ones. With that said, the paper will not digress further from its stated biological focus.

\section{MECHANISMS OF AGING}

The maximum lifespan is dependent not only on the genetic heterogeneity that characterizes different species, but also on variable environmental influences (17-20). These influences of both nature and nurture give rise to various aging phenotypes that cannot be easily explained by a single hypothesis. Instead, many theories based on fundamental molecular, cellular, and systemic analyses of aging have been developed in the last few decades. These theories, which are not necessarily mutually exclusive, have been classified by the National Institute of Aging into two major categories. Program theories hold that aging is the result of the sequential switching on and off of certain genes whereas error theories emphasize that aging is the outcome of both random accumulation of error mutations and wear and tear of tissues and organs during the lifespan of an organism. The following sections summarize examples of both types of theories of aging.

\section{ERROR THEORIES}

\section{Accumulation of mutations}

Somatic mutations, including gene mutations, gene conversion, and gene amplifications, chromosomal abnormalities, and mitotic recombinations, have been widely agreed to play important roles in the development of aging (for review, see reference 21). This hypothesis stemmed from the observation that damages induced by irradiation in animals resembled phenotypic changes in aging (22). Since radiation was well known to be able to induce mutations, aging could be caused by accumulation of mutations after life-long exposure to natural levels of background radiation and other environmental agents $(23,24)$. In fact, X-rayinduced chromosomal damages have been shown to shorten life expectancy (25). Another source of errors comes from DNA replications. It has been estimated that the error rate of DNA replication can be as high as $0.01 \%$ (26). There are systems to maintain the precision of DNA replications and, indeed, the ability to repair DNA in different organisms has been shown to correlate directly with their maximal lifespan $(27,28)$. However, the ability to repair DNA has been shown to decrease with age $(29,30)$. These two sources of damage, mutations by environmental factors and during DNA replication, may lead to significant levels of 
chromosomal abnormalities in aged tissue (30-34). Consistent with these mechanisms, aberrations of DNA material can be found in the nucleus (35) and the mitochondria of aged cells $(36,37)$.

One major criticism of the somatic mutation theory is that natural radiation under normal conditions may be too low to account for the overall age change $(30,38,39)$. However, recent findings from monitoring mutation of specific genes at different time points during life showed significant levels of mutation in aged tissue. For example, studying the mutation rate of the hypoxanthine phosphoribosyl transferase (HPRT) gene revealed significantly higher mutant frequencies in aged mice (40) and humans (41). Monitoring a neutral reporter gene lacI during the development of transgenic mice also revealed accumulation of mutations with age (42-44). Interestingly, animals with caloric restriction, the only intervention that appears to lengthen lifespan $(45,46)$, accumulate HPRT mutations at a much slower rate when compared with ad libitum fed animals $(40,47)$. On the contrary, accumulation of HPRT mutations is higher in the senescence accelerated mouse model, which develops aging phenotypes earlier than normal mice (48). Thus, accumulation of mutations could be a major factor in determining biological aging.

Although the somatic mutation theory predicts the accumulation of mutations randomly during aging, increasing evidence shows that some genes accumulate more errors than other genes with time. For instance, human leukocyte antigen (HLA) genes have a mutation frequency two to three times higher than that of HPRT genes (49). In addition, some regions of the genome display above average mutation rates. These mutation hot spots usually contain repeat elements $(50,51)$. One of the important examples is the telomere, which is present at the end of each DNA strand (for review, see reference 52). Accumulation of mutations in the minisatellite repeat elements of the telomere hinders the DNA synthesis machinery to replicate the very end of the lagging strand and results in chromosomal aberrations (53). Shortening of telomeres with age has been reported in different tissues (54). More importantly, reversing the shortening of telomeres has been shown to arrest the aging process. For instance, expressing telomerase, a ribonucleoprotein that is capable of correcting telomere shortening by adding TTAGGG repeats to chromosome ends, not only maintains the length of telomeres, but also extends the lifespan of human cell lines (55). Thus, even with a low overall mutation rate, the occurrence of high mutation rates in specific genomic locations in aging may result in substantial age-related functional alteration.

Accumulation of genetic errors may give rise to several cellular end points which are related to the development of aging. One of the major consequences of mutation load is cell death (56). Cell death has been shown to contribute to various age-related functional deficits, including heart failure (57), kidney dysfunction (58), and decline of immune function (59). Indeed, apoptosis could be a mechanism for removing aged cells during aging (60-62). Cell loss resulting from removal of mutated cells could be related to the functional decline with aging. Mutation load with aging could also result in alteration of gene expression. For instance, aberrant expression of globin RNA in the liver and brain of older mice is higher than in younger controls (63). In addition, DNA methylation at $\mathrm{CG}$ bases, which relates to inactivation of gene expression, has been shown to decrease with age $(64,65)$. These detrimental consequences of mutation load during aging could explain the development of functional age-related declines.

\section{Wear and Tear}

The wear and tear theory claims that with repeated use, parts in living organisms wear out and give rise to defects. These malfunctions provide the cellular substrate for the build up of physiological deficits in aging. The premise of this theory is based on the observation that the lifespan of poikilotherms is shortened by increasing the environmental temperature and prolonged by decreasing it $(66,67)$. Indeed, active tissues with high rates of cell turnover have been shown to contain more age-related lesions. For instance, more rapid telomere loss can be found in the endothelial lining of blood vessels that were exposed to high hemodynamic stress and underwent rapid turnover (68).

Apart from damages caused by repeated usage, various exogenous or endogenous agents can damage biological macromolecules with time. Among the most common endogenous agents is the free radical (for review, see reference 69). Free radicals are reactive molecules containing one or more unpaired electrons and are produced during normal oxidative metabolism $(70,71)$. Free radicals are able to attack other molecules indiscriminately and cause fragmentation or crosslinking of molecules (7). An increase in the level of free radicals was found in aged brains (72). The level of oxidized lipid (73) and protein (74) is also higher in aged tissue. In addition, cross linkage of both membranous structures (75) and DNA $(76,77)$ have been shown to increase with age. Mitochondrial DNA, which lacks the protection of histones and suffers more directly from the de novo production of free radicals, has been shown to mutate at a much higher rate than nuclear DNA (78). Interestingly, comparative studies also reveal an inverse correlation between the level of oxidative burden and maximum life expectancy in different organisms (79).

The production of free radicals is normally controlled by various protective systems in our body. They include enzymes like superoxide dismutase (SOD), catalase, and glutathione peroxidase that break down newly produced 
free radicals into less reactive derivatives (for review, see reference 80). Antioxidants like vitamin $\mathrm{E}$ and $\mathrm{C}$ also play important roles in reducing active free radicals (81). While contradicting findings on the effect of these antioxidant enzymes on aging was found (e.g. see reference 82), there is evidence of insufficient antioxidant activity in aged tissue. For instance, dietary supplements of free radicals scavengers has been shown to reduce agerelated declines in neuronal signal transduction and cognitive or motor behavioral deficits in aged rats (83). Indeed, some longevity genes have been shown to be related to the development of oxidative stress. For example, mutation of mev-1, which encodes a subunit of the enzyme succinate dehydrogenase cytochrome $b$, results in higher production of free radicals and shorter lifespan (84). Thus, increased free radical production and insufficient antioxidant activity in aged tissue may contribute to functional deficits with age.

\section{PROGRAM THEORIES}

The underlying assumption of program theories is the existence of genetic programs that determines the maximum lifespan for each species. Evidence to support these theories includes the observation of sequential activation and repression of genes during different stages of development. For instance, studies on rat liver cytosolic alanine aminotransferase (cAAT) have shown that the gene for A type cAAT is active in the early developmental stages and subsequently repressed. However, the expression of B type cAAT is only activated in old age (85). Similar programmed activation of some senescence markers has been reported. A liver protein named as senescence marker protein 2 is expressed maximally during prepuberty and older age (86).

Another important finding to support program theories of aging is the presence of longevity controlling genes. Mutation of some genes in the nematode Caenorhabditis elegans has been shown to extend life expectancy of the nematode by 40 to $100 \%$. Examples of these genes include age-1, daf-2, and $c l k-1$ genes (87-89). Life expectancy of a $d a f-2 / c l k-1$ double mutant is five times longer than that of the wild type (90). While program activation of these potential longevity genes may be important in determining the lifespan of different organisms, evidence for similar candidate longevity genes in humans is lacking.

\section{EXAMPLES OF THESE MECHANISMS IN NEURONAL AGING}

Because most neurons do not replicate, one would expect that they are protected against errors arising from DNA replication. However, due to the large size and high metabolic rate of neurons, neuronal survival depends on high rate of oxidative phosphorylation (91). This may result in a large amount of free radical production and thus confer the nervous system with a high vulnerability to oxidative stress. Indeed, this high neuronal vulnerability toward oxidative stress may be responsible for the mitochondrial DNA mutations $(92,93)$ and nuclear mutations $(77,94-96)$ observed in aged neuronal tissue.

Apart from inducing mutation, oxidative stress also plays important roles in the development of other agerelated neuronal damage. High levels of free radicals have been related to the etiology of neurodegenerative phenotype in Alzheimer's disease $(97,98)$ and Parkinson's disease $(99,100)$. For instance, oxidative stress has been shown to cause the death of dopaminergic neurons in Parkinson's disease $(101,102)$. Apoptosis can be induced by damage resulting from oxidative stress (for review, see reference 103).

While the mechanism by which free radicals damage neuronal tissue is still unknown, these reactive elements may play important roles in several age-related neuronal lesions. Oxidative stress has been suggested to cause accumulation of lipofuscin in the neurons from aged brains $(104,105)$. Diet supplement of vitamin E can reduce the density of lipofuscin in aged neurons (106). Lipid peroxidation of neuronal membrane induced by free radicals may also play important roles in the modification of neuronal structures. For instance, longterm (10 months) removal of vitamin $\mathrm{E}$ from the diet results in a significant decrease in the number of synapses in the cerebellum (107). Finally, not all neuronal structures or function are equally susceptible to oxidative damage. For instance, in vitro studies of the effect of $\mathrm{H}_{2} \mathrm{O}_{2}$ revealed no effects on excitatory synaptic transmission, whereas reductions in transmembrane $\mathrm{Cl}^{-}$ gradient and inhibitory neurotransmission were found (108). The observed disappearance of inhibitory inputs may result in a rise of the level of excitatory neurotransmitters, which increase the possibility of neuronal damage due to excitotoxicity (109-111).

Findings of roles played by different molecular and cellular factors in aging have helped us understand better the age-related change at the level of organs and systems. For instance, oxidative damages have been associated with the loss of synaptic connections in aged brain (107). This age-related loss of neuronal connectivity has been related to the reduced neuronal activity in aged brains $(112,113)$, which in turn may give rise to the development of age-related cognitive declines (114). However, translation of these cellular deficits into age-related pathologies is also difficult to understand. For example, reduction in synaptic structures in aged brain does not always result in an alteration of neuronal function. In fact, physiological compensation after the loss of synapses in aging by the neuronal circuitry has been reported in the hippocampus (115) and cerebral cortex (116). A more thorough comprehension of agerelated changes in molecular, organic, and systemic 
levels is therefore necessary to uncover the underlying mechanism of age-related pathologies.

\section{SUMMARY}

Aging results from a complex interplay between multiple different mechanisms. The predominant mechanism or combination of mechanisms depends on the particular tissue or cell type in question. Nonetheless, a common theme is alteration of gene products or expression. This may occur accidentally over time because of either intrinsic or extrinsic factors, or it may represent part of a predetermined sequence of events. However, it is often difficult to identify whether altered expression of a certain gene is the primary cause or if it is secondary to some other factor, and even gene mutation can represent reduced capacity for repair rather than increased rates of mutation per se. Another level of complexity is added to the picture when one considers how the primary changes are manifested at the level of cells, tissues, and organs, let alone the organism as a whole. In turn, developing treatments to delay or ameliorate age-related deterioration of function is a complicated task, but it will ultimately benefit from detailed understanding of the underlying changes.

\section{REFERENCES}

1. Statistics Canada. Population projections for 2001, 2006, 2011, 2016, 2021 and 2026. http://www.statcan.ca/english/Pgdb/ People/popula.htm\#pop. 2000.

2. Day JC. Population projections of the United States by age, sex, race, and Hispanic origin: 1995 to 2000. Current Population Reports, 25. Washington, DC: Bureau of the Census, U.S. Printing Office; 1996.

3. National Center for Health Statistics. Vital Statistics of the United States. 1995, II, Part A, section 6, 14. Hyattsville, MD: DHHS Publication; 1998.

4. Crimmins EM, Saito Y, Reynolds SL. Further evidence on recent trends in the prevalence and incidence of disability among older Americans from two sources: the LSOA and the NHIS. Journal of Gerontology B Psychological Sciences and Social Sciences 1997; 52: S59-S71.

5. Schneider EL. Aging in the third millennium. Science 1999; 283: 796-797.

6. Comfort A. The Biology of Senescence. London: Churchill Livingstone; 1979.

7. Harman D. The aging process: major risk factor for disease and death. Proceedings of the National Academy of Sciences USA 1991; 88: 5360-5363.

8. Busse EW. Primary and secondary aging. In: Maddox GL, Roth G, Atchley R, eds. The Encyclopedia of Aging. New York: Springer; 1987: 534.

9. Lim SY, Suzuki H. Intakes of dietary docosahexaenoic acid ethyl ester and egg phosphatidylcholine improve maze-learning ability in young and old mice. Journal of Nutrition 2000; 130: 1629-1632.

10. Lopes LV, Cunha RA, Ribeiro JA. Cross talk between A(1) and $\mathrm{A}(2 \mathrm{~A})$ adenosine receptors in the hippocampus and cortex of young adult and old rats. Journal of Neurophysiology 1999; 82: 3196-3203.

11. Swenson KL, Sands JM, Jacobs JD, Sladek CD. Effect of aging on vasopressin and aquaporin responses to dehydration in Fischer 344-brown-Norway F1 rats. American Journal of Physiology 1997; 273: R35-R40.

12. Walford RL. Letter: When is a mouse "old"? Journal of Immunology 1976; 117: 352.

13. Wexler BC. Co-existent arteriosclerosis, PAN, and premature aging. Journal of Gerontology 1970; 25: 373-380.

14. Schlettwein-Gsell D. Survival curves of an old age rat colony. Gerontologia 1970; 16: 111-115.

15. Sass B, Rabstein LS, Madison R, et al. Incidence of spontaneous neoplasms in F344 rats throughout the natural life-span. Journal of the National Cancer Institute 1975; 54: 1449-1456.

16. Burek JD, Hollander CF. Incidence patterns of spontaneous tumors in $\mathrm{BN} / \mathrm{Bi}$ rats. Journal of the National Cancer Institute 1977; 58: 99-105.

17. Austad SN. Theories of aging: an overview. Aging (Milano) 1998; 10: 146-147.

18. Olson CB. A review of why and how we age: a defense of multifactorial aging. Mechanisms of Ageing and Development 1987; 41: 1-28.

19. Lithgow GJ, Kirkwood TB. Mechanisms and evolution of aging. Science 1996; 273: 80 .

20. Eichhorn GL. Aging, genetics, and the environment: potential of errors introduced into genetic information transfer by metal ions. Mechanisms of Ageing and Development 1979; 9: 291-301.

21. Vijg J. Somatic mutations and aging: a re-evaluation. Mutation Research 2000; 447: 117-135.

22. Henshaw PS, Riley EF, Stapleton GE. The biologic effects of pile radiations. Radiology 1947; 49: 349-364.

23. Szilard L. On the nature of the aging process. Proceedings of the National Academy of Sciences USA 1959; 45: 30-35.

24. Failla G. The aging process and carcinogenesis. Annals of the New York Academy of Science 1958; 71: 1124-1135.

25. Curtis HJ. Cellular processes involved in aging. Federation Proceedings 1964; 23: 662-665.

26. Dani SU. Mechanisms of aging: a survey. In: Dani SU, Hori A Walter GF, eds. Principles of Neural Aging. Amsterdam: Elsevier; 1997: 5-17.

27. Hall KY, Hart RW, Benirschke AK, Walford RL. Correlation between ultraviolet-induced DNA repair in primate lymphocytes and fibroblasts and species maximum achievable life span Mechanisms of Ageing and Development 1984; 24: 163-173.

28. Maslansky CJ, Williams GM. Ultraviolet light-induced DNA repair synthesis in hepatocytes from species of differing longevities. Mechanisms of Ageing and Development 1985; 29: 191-203.

29. Hart RW, Setlow RB. Correlation between deoxyribonucleic acid excision-repair and life-span in a number of mammalian species. Proceedings of the National Academy of Sciences USA 1974; 71: 2169-2173.

30. Rattan SI. DNA damage and repair during cellular aging. International Review of Cytology 1989; 116: 47-88.

31. Curtis H, Crowley C. Chromosome aberrations in liver cells in relation to the somatic mutation theory of aging. Radiation Research 1963; 19: 337-344.

32. Crowley K, Curtis HJ. The development of somatic mutations in mice with age. Proceedings of the National Academy of Sciences USA 1963; 49: 626-628.

33. Hayflick L. Current theories of biological aging. Federation Proceedings 1975; 34: 9-13.

34. Tucker JD, Spruill MD, Ramsey MJ, et al. Frequency of spontaneous chromosome aberrations in mice: effects of age. Mutation Research 1999; 425: 135-141.

35. Ono $\mathrm{T}$, Miyamura $\mathrm{Y}$, Ikehata $\mathrm{H}$, et al. Spontaneous mutant frequency of lac $Z$ gene in spleen of transgenic mouse increases with age. Mutation Research 1995; 338: 183-188. 
36. Rose MR, Archer MA. Genetic analysis of mechanisms of aging. Current Opinion in Genetics and Development 1996; 6: 366-370.

37. Wallace DC. Mitochondrial genetics: a paradigm for aging and degenerative diseases? Science 1992; 256: 628-632.

38. Maynard Smith J. A theory of ageing. Nature 1959; 184: 956-957.

39. Kirkwood TB. DNA, mutations and aging. Mutation Research 1989; 219: 1-7.

40. Dempsey JL, Pfeiffer M, Morley AA. Effect of dietary restriction on in vivo somatic mutation in mice. Mutation Research 1993; 291: 141-145.

41. Jones IM, Thomas CB, Tucker B, et al. Impact of age and environment on somatic mutation at the hprt gene of $\mathrm{T}$ lymphocytes in humans. Mutation Research 1995; 338: 129-139.

42. Lee AT, DeSimone C, Cerami A, Bucala R. Comparative analysis of DNA mutations in lacI transgenic mice with age. FASEB Journal 1994; 8: 545-550.

43. Martus HJ, Dolle ME, Gossen JA, et al. Use of transgenic mouse models for studying somatic mutations in aging. Mutation Research 1995; 338: 203-213.

44. Ono T, Ikehata H, Nakamura S, et al. Age-associated increase of spontaneous mutant frequency and molecular nature of mutation in newborn and old lacZ-transgenic mouse. Mutation Resesarch 2000; 447: 165-177.

45. Weindruch R. Caloric restriction and aging. Scientific American 1996; 274: 46-52.

46. Nicolas AS, Lanzmann-Petithory D, Vellas B. Caloric restriction and aging. Journal of Nutrition, Health and Aging 1999; 3: 77-83.

47. Aidoo A, Desai VG, Lyn-Cook LE, et al. Attenuation of bleomycin-induced Hprt mutant frequency in female and male rats by calorie restriction. Mutation Research 1999; 430: 155-163.

48. Odagiri Y, Uchida H, Hosokawa M, et al. Accelerated accumulation of somatic mutations in the senescenceaccelerated mouse. Nature Genetics 1998; 19: 116-117.

49. Grist SA, McCarron M, Kutlaca A, et al. In vivo human somatic mutation: frequency and spectrum with age. Mutation Research 1992; 266: 189-196.

50. Dubrova YE, Jeffreys AJ, Malashenko AM. Mouse minisatellite mutations induced by ionizing radiation. Nature Genetics 1993; 5: 92-94.

51. Wong LJ, Ashizawa T, Monckton DG, et al. Somatic heterogeneity of the CTG repeat in myotonic dystrophy is age and size dependent. American Journal of Human Genetics 1995; 56: 114-122.

52. McEachern MJ, Krauskopf A, Blackburn EH. Telomeres and their control. Annual Review of Genetics 2000; 34: 331-358.

53. Olovnikov AM. A theory of marginotomy. The incomplete copying of template margin in enzymic synthesis of polynucleotides and biological significance of the phenomenon. Journal of Theoretical Biology 1973; 41: 181-190.

54. Butler MG, Tilburt J, DeVries A, et al. Comparison of chromosome telomere integrity in multiple tissues from subjects at different ages. Cancer Genetics and Cytogenetics 1998; 105: 138-144.

55. Bodnar AG, Ouellette M, Frolkis M, et al. Extension of life-span by introduction of telomerase into normal human cells. Science 1998; 279: 349-352.

56. Moustacchi E. DNA damage and repair: consequences on doseresponses. Mutation Research 2000; 464: 35-40.

57. Heinrich H, Holz J. Myocardial apoptosis in the overloaded and the aging heart: a critical role of mitochondria? European Cytokine Network 1998; 9: 693-695.

58. Singhal PC, Reddy K, Franki N, et al. Age and sex modulate renal expression of SGP-2 and transglutaminase and apoptosis of splenocytes, thymocytes, and macrophages. Journal of Investigative Medicine 1997; 45: 567-575.

59. Ginaldi L, De Martinis M, D’Ostilio A, et al. Cell proliferation and apoptosis in the immune system in the elderly. Immunology Research 2000; 21: 31-38.

60. Franceschi C. Cell proliferation, cell death and aging. Aging (Milano) 1989; 1: 3-15.

61. Barr PJ, Tomei LD. Apoptosis and its role in human disease. Biotechnology (NY) 1994; 12: 487-493.

62. Warner HR, Fernandes G, Wang E. A unifying hypothesis to explain the retardation of aging and tumorigenesis by caloric restriction. Journal of Gerontology A Biological Sciences and Medical Sciences 1995; 50: B107-B109.

63. Wareham KA, Lyon MF, Glenister PH, Williams ED. Age related reactivation of an X-linked gene. Nature 1987; 327: 725-727.

64. Singhal RP, Mays-Hoopes LL, Eichhorn GL. DNA methylation in aging of mice. Mechanisms of Ageing and Development 1987; 41: 199-210.

65. Holliday R. Strong effects of 5-azacytidine on the in vitro lifespan of human diploid fibroblasts. Experimental Cell Research 1986; 166: 543-552.

66. Fanestil DD, Barrows CH Jr. Aging in the rotifer. Journal of Gerontology 1965; 20: 462-469.

67. Strehler BL. Further studies on the thermally induced aging of Drosophila melanogaster. Journal of Gerontology 1962; 17: 347-352.

68. Chang E, Harley CB. Telomere length and replicative aging in human vascular tissues. Proceedings of the National Academy of Sciences USA 1995; 92: 11190-11194.

69. Mehlhorn RJ. Oxidants and antioxidants in aging. In: Timiras PS, ed. Physiological Basis of Aging and Geriatrics. Florida: CRC Press, Inc.; 1994: 61-73.

70. Chance B, Sies H, Boveris A. Hydroperoxide metabolism in mammalian organs. Physiological Reviews 1979; 59: 527-605.

71. Liu SS. Generating, partitioning, targeting and functioning of superoxide in mitochondria. Bioscience Reports 1997; 17: 259-272.

72. Sohal RS, Sohal BH. Hydrogen peroxide release by mitochondria increases during aging. Mechanisms of Ageing and Development 1991; 57: 187-202.

73. Rikans LE, Hornbrook KR. Lipid peroxidation, antioxidant protection and aging. Biochimica et Biophysica Acta 1997; 1362: 116-127.

74. Berlett BS, Stadtman ER. Protein oxidation in aging, disease, and oxidative stress. Journal of Biologica Chemstry 1997; 272: 20313-20316.

75. Gaczynska M, Bartosz G. Crosslinking of membrane proteins during erythrocyte ageing. International Journal of Biochemistry 1986; 18: 377-382.

76. Izzotti A, Cartiglia C, Taningher $\mathrm{M}$, et al. Age-related increases of 8-hydroxy-2'-deoxyguanosine and DNA-protein crosslinks in mouse organs. Mutation Research 1999; 446: 215-223.

77. Zahn RK, Zahn-Daimler G, Ax S, et al. Assessment of DNAprotein crosslinks in the course of aging in two mouse strains by use of a modified alkaline filter elution applied to whole tissue samples. Mechanisms of Ageing and Development 1999; 108: 99-112.

78. Richter C. Oxidative damage to mitochondrial DNA and its relationship to ageing. International Journal of Biochemistry and Cell Biology 1995; 27: 647-653.

79. Herrero A, Barja G. $\mathrm{H}_{2} \mathrm{O}_{2}$ production of heart mitochondria and aging rate are slower in canaries and parakeets than in mice: sites of free radical generation and mechanisms involved. Mechanisms of Ageing and Development 1998; 103: 133-146.

80. Mates JM, Sanchez-Jimenez F. Antioxidant enzymes and their implications in pathophysiologic processes. Frontiers in Bioscience 1999; 4: D339-D345.

81. Jovanovic SV, Simic MG. Antioxidants in nutrition. Annals of the New York Academy of Science 2000; 899: 326-334. 
82. Yargicoglu P, Agar A, Gumuslu S, et al. Age-related alterations in antioxidant enzymes, lipid peroxide levels, and somatosensory-evoked potentials: effect of sulfur dioxide. Archives of Environmental Contamination and Toxicology 1999; 37: 554-560

83. Joseph JA, Shukitt-Hale B, Denisova NA, et al. Reversals of age-related declines in neuronal signal transduction, cognitive, and motor behavioral deficits with blueberry, spinach, or strawberry dietary supplementation. Journal of Neuroscience 1999; 19: 8114-8121.

84. Ishii N, Fujii M, Hartman PS, et al. A mutation in succinate dehydrogenase cytochrome b causes oxidative stress and ageing in nematodes. Nature 1998; 394: 694-697.

85. Patnaik SK, Kanungo MS. Soluble alanine aminotransferase of the liver of rats of various ages: induction, characterization and changes in patterns. Indian Journal of Biochemistry and Biophysics 1976; 13: 117-124.

86. Chatterjee B, Roy AK. Changes in hepatic androgen sensitivity and gene expression during aging. Journal of Steroid Biochemistry and Molecular Biology 1990; 37: 437-445.

87. Morris JZ, Tissenbaum HA, Ruvkun G. A phosphatidylinositol3-OH kinase family member regulating longevity and diapause in Caenorhabditis elegans. Nature 1996; 382: 536-539.

88. Kimura KD, Tissenbaum HA, Liu Y, Ruvkun G. daf-2, an insulin receptor-like gene that regulates longevity and diapause in Caenorhabditis elegans. Science 1997; 277: 942-946.

89. Ewbank JJ, Barnes TM, Lakowski B, et al. Structural and functional conservation of the Caenorhabditis elegans timing gene $c l k$ - 1 . Science 1997; 275: 980-983.

90. Lakowski B, Hekimi S. Determination of life-span in Caenorhabditis elegans by four clock genes. Science 1996; 272 : 1010-1013.

91. Aiello GL, Rita P. The cost of an action potential. Journal of Neuroscience Methods 2000; 103: 145-149.

92. Filburn CR, Edris W, Tamatani M, et al. Mitochondrial electron transport chain activities and DNA deletions in regions of the rat brain. Mechanisms of Ageing and Development 1996; 87: 35-46.

93. Sastre J, Pallardo FV, Garcia de la Asuncion J, Vina J. Mitochondria, oxidative stress and aging. Free Radical Research 2000; 32: 189-198

94. Kaneko T, Tahara S, Matsuo M. Non-linear accumulation of 8 hydroxy-2'-deoxyguanosine, a marker of oxidized DNA damage, during aging. Mutation Research 1996; 316: 277-285.

95. Randerath K, Putman KL, Osterburg HH, et al. Age-dependent increases of DNA adducts (I-compounds) in human and rat brain DNA. Mutation Research 1993; 295: 11-18.

96. Mandavilli BS, Rao KS. Neurons in the cerebral cortex are most susceptible to DNA-damage in aging rat brain. Biochemistry and Molecular Biology International 1996; 40: 507-514.

97. Perry G, Nunomura A, Hirai K, et al. Oxidative damage in Alzheimer's disease: the metabolic dimension. International Journal of Developmental Neuroscience 2000; 18: 417-421.

98. Christen Y. Oxidative stress and Alzheimer disease. American Journal of Clinical Nutrition 2000; 71: 621S-629S

99. Offen D, Hochman A, Gorodin S, et al. Oxidative stress and neuroprotection in Parkinson's disease: implications from studies on dopamine-induced apoptosis. Advances in Neurology 1999; 80: 265-269.

100. Youdim MB, Riederer P. Understanding Parkinson's disease. Scientific American 1997; 276: 52-59.

101. Gerlach M, Desser H, Youdim MB, Riederer P. New horizons in molecular mechanisms underlying Parkinson's disease and in our understanding of the neuroprotective effects of selegiline. Journal of Neural Transmission Suppl. 1996; 48: 7-21.

102. Naoi M, Maruyama W. Cell death of dopamine neurons in aging and Parkinson's disease. Mechanisms of Ageing and Development 1999; 111: 175-188.

103. Sastry PS, Rao KS. Apoptosis and the nervous system. Journal of Neurochemistry 2000; 74: 1-20.

104. Sohal RS, Brunk UT. Lipofuscin as an indicator of oxidative stress and aging. Advances in Experimental Medicine and Biology 1989; 266: 17-26.

105. Oenzil F, Kishikawa M, Mizuno T, Nakano M. Age-related accumulation of lipofuscin in three different regions of rat brain. Mechanisms of Ageing and Development 1994; 76: 157-163.

106. Monji A, Morimoto N, Okuyama I, et al. Effect of dietary vitamin $\mathrm{E}$ on lipofuscin accumulation with age in the rat brain. Brain Research 1994; 634: 62-68.

107. Bertoni-Freddari C, Giuli C, Pieri C. Effect of chronic vitamin E deficiency on the synapses of cerebellar glomeruli in young rats. Mechanisms of Ageing and Development 1984; 24: 225-232.

108. Sah R, Schwartz-Bloom RD. Optical imaging reveals elevated intracellular chloride in hippocampal pyramidal neurons after oxidative stress. Journal of Neuroscience 1999; 19: 9209-9217.

109. Saransaari P, Oja SS. Enhanced GABA release in cell-damaging conditions in the adult and developing mouse hippocampus. International Journal of Developmental Neuroscience 1997; 15: 163-174.

110. Green AR, Hainsworth AH, Jackson DM. GABA potentiation: a logical pharmacological approach for the treatment of acute ischaemic stroke. Neuropharmacology 2000; 39: 1483-1494.

111. Lyden PD. GABA and neuroprotection. International Review of Neurobiology 1997; 40: 233-258.

112. Lippa AS, Critchett DJ, Ehlert F, et al. Age-related alterations in neurotransmitter receptors: an electrophysiological and biochemical analysis. Neurobiology of Aging 1981; 2: 3-8.

113. Stern WC, Pugh WW, Morgane PJ. Single unit activity in frontal cortex and caudate nucleus of young and old rats. Neurobiology of Aging 1985; 6: 245-248.

114. Grady CL, Craik FI. Changes in memory processing with age. Current Opinion in Neurobiology 2000; 10: 224-231.

115. Barnes CA. Normal aging: regionally specific changes in hippocampal synaptic transmission. Trends in Neurosciences 1994; 17: 13-18.

116. Wong TP, Marchese G, Casu MA, et al. Loss of presynaptic and postsynaptic structures is accompanied by compensatory increase in action potential-dependent synaptic input to layer $\mathrm{V}$ neocortical pyramidal neurons in aged rats. Journal of Neuroscience 2000; 20: 8596-8606.

Tak Pan Wong received his B.Sc. in Biology and M.Phil. in Physiology from University of Hong Kong (Hong Kong, PRC). He has recently finished his Ph.D., which focused on the cortical synaptic modification in aging at McGill University (Montreal, Quebec, Canada). During his Ph.D. study, he received awards from the Croucher Foundation (Hong Kong), FRSQ-FCAR-Santé, and the Alzheimer Society of Canada. Dr. Wong has been recently awarded a post-doctoral fellowship from NSERC for commencing his research training in the Hospital for Sick Children in Toronto, Canada. 